\title{
Expression and Localization of Macrophage Elastase (Matrix Metalloproteinase-12) in Abdominal Aortic Aneurysms
}

\author{
John A. Curci, ${ }^{\star}$ Shixiong Liao, ${ }^{\star}$ Mark D. Huffman, ${ }^{\star}$ Steven D. Shapiro, ${ }^{\ddagger}$ and Robert W. Thompson ${ }^{\star \S}$ \\ $*$ Section of Vascular Surgery, Department of Surgery, ${ }^{*}$ Division of Pulmonary and Critical Care Medicine, Department of Medicine, and \\ ${ }^{\S}$ Department of Cell Biology and Physiology, Washington University School of Medicine, St. Louis, Missouri 63110
}

\begin{abstract}
Elastolytic matrix metalloproteinases (MMPs) have been implicated in the pathogenesis of abdominal aortic aneurysms (AAA), a disorder characterized by chronic aortic wall inflammation and destruction of medial elastin. The purpose of this study was to determine if human macrophage elastase (HME; MMP-12) might participate in this disease. By reverse transcription-polymerase chain reaction, HME mRNA was consistently demonstrated in AAA and atherosclerotic occlusive disease (AOD) tissues (six of six), but in only one of six normal aortas. Immunoreactive proteins corresponding to proHME and two products of extracellular processing were present in seven of seven AAA tissue extracts. Total HME recovered from AAA tissue was sevenfold greater than normal aorta $(P<0.001)$, and the extracted enzyme exhibited activity in vitro. Production of HME was demonstrated in the media of AAA tissues by in situ hybridization and immunohistochemistry, but HME was not detected within the media of normal or AOD specimens. Importantly, immunoreactive HME was specifically localized to residual elastin fragments within the media of AAA tissue, particularly areas adjacent to nondilated normal aorta. In vitro, the fraction of MMP-12 sequestered by insoluble elastin was two- to fivefold greater than other elastases found in AAA tissue. Therefore, HME is prominently expressed by aneurysm-infiltrating macrophages within the degenerating aortic media of AAA, where it is also bound to residual elastic fiber fragments. Because elastin represents a critical component of aortic wall structure and a matrix substrate for metalloelastases, HME may have a direct and singular role in the pathogenesis of aortic aneurysms. (J. Clin. Invest. 1998. 102:1900-1910.) Key words: aortic aneurysm - elastin - matrix metalloproteinases • mononuclear phagocytes • macrophage elastase
\end{abstract}

Portions of this work were presented at Experimental Biology '97, New Orleans, LA, in April 1997 and were published in abstract form (1997. FASEB [Fed. Am. Soc. Exp. Biol.] J. 11:A336).

Address correspondence to Robert W. Thompson, M.D., Section of Vascular Surgery, Washington University School of Medicine, 9901 Wohl Hospital, 4960 Children's Place, St. Louis, MO 63110. Phone: 314-362-7410; FAX: 314-747-3548; E-mail: thompsonr@msnotes. wustl.edu

Received for publication 6 November 1997 and accepted in revised form 1 October 1998.

J. Clin. Invest.

(C) The American Society for Clinical Investigation, Inc. 0021-9738/98/12/1900/11 \$2.00

Volume 102, Number 11, December 1998, 1900-1910

http://www.jci.org

\section{Introduction}

Abdominal aortic aneurysms (AAA) ${ }^{1}$ represent a potentially fatal disorder that affects $2-9 \%$ of the population $>65 \mathrm{yr}$ of age (1-3). Numerous clinical studies have established associations between AAA and aging, atherosclerosis, and male gender, as well as cigarette smoking, pulmonary emphysema, and high blood pressure (4). Aneurysms also occur with a familial tendency that suggests a genetically inherited component to the disease (5-8), but specific gene defects underlying the common forms of AAA have yet to be identified $(9,10)$. Whereas aneurysmal degeneration is thought to arise through mechanisms of vascular wall remodeling distinct from those observed in either aging, atherosclerosis, or hypertension alone, the etiology of AAA remains unresolved (11-13).

Tissue remodeling in aneurysms is characterized by destruction of the structural and cellular components of the aortic wall in association with chronic transmural inflammation (11-13). The most prominent of these features is progressive irreversible degeneration of the elastic media (14-16), a significant finding given the biologic stability of elastin in tissue (17, 18). Biophysical alterations associated with the loss of aortic elastin are considered functionally responsible for aneurysmal dilatation and tortuosity (19-22). Processes associated with the destruction of aortic elastin include infiltration of the aortic media by mononuclear inflammatory cells $(23,24)$, deposition of IgG recognizing elastic fiber components $(25,26)$, medial neovascularization (27), and a decrease in medial smooth muscle cell density (28). These processes are associated with increased local production of cytokines, chemokines, and prostaglandins (29-31), as well as fibrinolytic and matrix-degrading proteinases (32-34).

Recent studies indicate that the connective tissue destruction in aortic aneurysms is likely mediated by matrix metalloproteinases (MMPs), a family of structurally related proteinases involved in developmental tissue remodeling, wound repair, chronic inflammatory diseases, and cancer $(35,36)$. Four members of this family are known to be capable of degrading insoluble elastic fibers under physiologic conditions: the 92- and 72-kD gelatinases (MMP-9 and MMP-2, respectively) (37), matrilysin (MMP-7) (38), and the more recently described macrophage elastase (MMP-12) (39). MMP-9 and MMP-2 are the most prominent elastolytic activities secreted by human AAA tissues in organ culture $(32,40)$, and both of these enzymes are expressed in human AAA tissue $(32,41$, 42). Although tissue inhibitors of metalloproteinases (TIMPs) are also overproduced in human AAA tissue $(32,40,41)$, it re-

1. Abbreviations used in this paper: AAA, abdominal aortic aneurysm; AOD, atherosclerotic occlusive disease; DAB, diaminobenzidine; HME, human macrophage elastase; HNE, human neutrophil elastase; MME, mouse macrophage elastase; MMP, matrix metalloproteinase; PPE, porcine pancreatic elastase; RT-PCR, reverse transcription-PCR; TIMP, tissue inhibitor of metalloproteinase. 
mains unclear if elastin-degrading MMPs can be completely sequestered by TIMPs in vivo $(43,44)$.

In contrast to $92-$ and $72-\mathrm{kD}$ gelatinases, knowledge is limited regarding the role of either human macrophage elastase (HME) or matrilysin in vascular disease. MMP-12 is known to be prominently expressed in human carotid atherosclerotic lesions (45), and by foam cells associated with aortic lesions in cholesterol-fed rabbits (46). It is also present in apo E-deficient mice, which develop complex aortic lesions with microaneurysm formation (47). Therefore, we predicted that HME might also play an important role in human AAA. The investigations reported here demonstrate for the first time that HME is produced in human AAA tissue and is expressed by aneurysm-infiltrating macrophages in vivo. Importantly, macrophage elastase is also prominently localized to residual elastin fiber fragments within aneurysm tissue by immunohistochemistry, a pattern distinct from other elastolytic MMPs. The elevated production of HME and its unique localization to fragmented aortic elastin suggest a particularly important role for this enzyme in aneurysmal degeneration.

\section{Methods}

Human aortic tissues. Fresh aortic wall specimens were obtained in the operating room from normal organ transplant donors without visible evidence of aortic atherosclerosis $(n=12)$, and from 27 patients undergoing aortic reconstruction for either atherosclerotic occlusive disease (AOD; $n=12)$ or infrarenal AAA $(n=15)$. All tissue specimens were taken after a protocol approved by the Washington University School of Medicine Human Research Subjects Committee. In addition to AAA specimens from the mid-portion of the aneurysm, in several instances a longitudinal specimen of aortic wall was also obtained from the transition zone between the normal (nondilated) infrarenal aorta and the proximal aspect of the aneurysm. One portion of each aortic wall specimen was fixed overnight in $10 \%$ neutral buffered formalin and processed for routine embedding in paraffin. An adjacent portion was snap-frozen in liquid nitrogen, stored at $-80^{\circ} \mathrm{C}$, and subsequently used for protein and nucleic acid extraction.

Immunoblot analysis of HME. Frozen aortic tissue samples were pulverized under liquid nitrogen and extracted in ice-cold $50 \mathrm{mM}$ Tris- $\mathrm{HCl}$ buffer, $\mathrm{pH} 7.5$, containing $1.0 \mathrm{M} \mathrm{NaCl}, 2.0 \mathrm{M}$ urea, $0.1 \%$ (wt/vol) Brij-35, 0.1\% EDTA, and a mixture of serine, cysteine, and aspartic protease inhibitors (protease inhibitor cocktail No. P8340; Sigma Chemical Co., St. Louis, MO). After centrifugation at $10,000 \mathrm{~g}$ for $1 \mathrm{~h}$ at $4^{\circ} \mathrm{C}$, the supernatant was centrifugally concentrated using a 5,000 molecular weight cut-off membrane for $2 \mathrm{~h}$ at $4^{\circ} \mathrm{C}$. Samples were normalized to total protein content and resolved by SDS-PAGE under nonreducing conditions, using $12 \%$ polyacrylamide gels. Proteins were transferred to nitrocellulose, blocked with $5 \%$ powdered milk in TBS $(20 \mathrm{mM}$ Tris $\mathrm{HCl}, \mathrm{pH} 7.5,0.5 \mathrm{M} \mathrm{NaCl})$, then incubated overnight at $4^{\circ} \mathrm{C}$ with affinity-purified rabbit antibodies to the aminoterminal portion of HME (39). Peroxidase-conjugated goat anti-rabbit IgG (Jackson ImmunoResearch, West Grove, PA) was used as the secondary antibody and immune complexes were visualized by ECL using kit reagents (Amersham Life Science, Inc., Arlington Heights, IL). The relative density of immunoreactive HME was determined with 1D Plus Densitometry software from Phoretix (Newcastle Upon Tyne, UK). The amount of HME recovered in extracts of normal aorta, AOD, and AAA was determined as the mean \pm SEM of relative densities for all samples of each tissue type and data were compared using ANOVA and the Newman-Student-Keul's multiple comparisons test (48).

Specificity of anti-HME antibodies. Additional assays were performed to exclude cross-reactivity of the anti-HME antibodies to elastic fiber components. Human soluble aortic elastin, human solu- ble lung elastin, bovine soluble nuchal ligament elastin, alpha-elastin, ETNA (kappa)-elastin, and Leu-Gly-Thr-Ile-Pro-Gly were all purchased from Elastin Products Co. (Owensville, MO). Chondroitin sulfate and the elastin-specific peptide Val-Gly-Val-Ala-Pro-Gly were obtained from Sigma. Collagen type IV was purchased from GIBCO BRL (Gaithersburg, MD). Recombinant HME was expressed in Escherichia coli and the 22-kD active form was purified as described previously (39). Each protein was blotted onto a nitrocellulose membrane at room temperature using a slot blotting apparatus from Bio-Rad (Richmond, CA). The membrane was washed, blocked with $3 \%$ gelatin, then incubated for $20 \mathrm{~h}$ at $4^{\circ} \mathrm{C}$ with affinity-purified rabbit anti-HME antibody, monoclonal mouse anti-human elastin (Sigma), or monoclonal mouse anti-collagen type IV (Sigma). Immune complexes were detected and quantified as described above.

Substrate gel zymography. Aortic tissue proteins were extracted as described above for immunoblotting. No additional steps were taken to remove EDTA during sample preparation for substrate zymography, because preliminary experiments demonstrated that this was not necessary to effectively detect enzymatic activities. Samples were resolved through $10 \%$ polyacrylamide gels copolymerized with $1 \mathrm{mg} / \mathrm{ml} \alpha$-casein (Sigma), as described (37), then washed with $2.5 \%$ Triton X-100 and incubated for $48 \mathrm{~h}$ in substrate buffer (50 mM Tris$\mathrm{HCl}, \mathrm{pH} 8.5,5 \mathrm{mM} \mathrm{CaCl}_{2}$, and $0.02 \% \mathrm{NaN}_{3}$ ) at $37^{\circ} \mathrm{C}$. After staining with $0.1 \%$ Coomassie blue R-250, casein-degrading activities were observed as clear bands against a dark background of intact substrate.

Reverse transcription-PCR (RT-PCR). Total RNA was isolated from aortic tissue samples by guanidium isothiocyanate-phenol-chloroform extraction as described by Chomczynski and Sacchi (49). All samples were normalized to total RNA and each sample was analyzed in duplicate, along with controls for genomic DNA (absence of reverse transcriptase) and for nonspecific DNA contamination (absence of RNA template). First strand cDNA synthesis was performed in a 20- $\mu \mathrm{l}$ reaction volume using $0.1 \mu \mathrm{g}$ of total RNA, $20 \mathrm{U}$ RNase inhibitor, $2.5 \mu \mathrm{M}$ random hexamers, $1 \mathrm{mM}$ dNTPs, and $50 \mathrm{U}$ murine leukemia virus reverse transcriptase, as provided in the GeneAmp RNA PCR kit from Perkin-Elmer (Norwalk, CT). Samples were incubated at $42^{\circ} \mathrm{C}$ for $15 \mathrm{~min}$ and the reaction was terminated by heating to $99^{\circ} \mathrm{C}$ for $5 \mathrm{~min}$. RT products served as the template for PCR amplification, using primers for HME exons 4-7 (synthesized by GIBCO BRL): 5'-TCACGAGATTGGCCATTCCTT-3' (forward primer, bp 663-683) and 5'-TCTGGCTTCAATTTCATAAGC-3' (reverse complement primer, bp 1015-1035). PCR amplifications were performed in a $100-\mu \mathrm{l}$ reaction with $10 \mathrm{mM}$ Tris- $\mathrm{HCl}$ buffer containing $50 \mathrm{mM} \mathrm{KCl}, 2 \mathrm{mM} \mathrm{MgCl}$, 100 pmol (each) forward and reverse complement primers, and $2.5 \mathrm{U}$ of AmpliTaq DNA polymerase. Reactions included $4 \mathrm{~min}$ at $95^{\circ} \mathrm{C}$ for denaturation and 30 cycles of $1 \mathrm{~min}$ at $95^{\circ} \mathrm{C}, 1 \mathrm{~min}$ at $55^{\circ} \mathrm{C}$, and $1 \mathrm{~min}$ at $72^{\circ} \mathrm{C}$; samples were then incubated for $7 \mathrm{~min}$ at $72^{\circ} \mathrm{C}$ for final extension before holding at $4^{\circ} \mathrm{C}$. A $30-\mu l$ aliquot of each sample was resolved by electrophoresis through $1.2 \%$ agarose in the presence of $5 \mathrm{ng} / \mathrm{ml}$ ethidium bromide, and DNA was visualized under ultraviolet light to detect the presence of PCR amplification products at the anticipated size (261 bp).

RT-PCR products were transferred from agarose to Hybond $\mathrm{N}^{+}$ nylon membranes (Amersham) by standard Southern transfer techniques. Hybridization was performed with a cDNA oligonucleotide probe specific for HME (5'-CATACGTGGCATTCAGTCCCT-3', bp 774-794 in exon 5), using an ECL $3^{\prime}$ oligolabeling and detection system purchased from Amersham. Membranes were incubated at $42^{\circ} \mathrm{C}$ for $90 \mathrm{~min}$ with $10 \mathrm{ng} / \mathrm{ml}$ labeled cDNA, washed under stringent conditions, and incubated with ECL detection reagents before exposure to radiographic film. For all samples of each aortic tissue type examined (normal, AOD, and AAA; $n=6$ each), consistent hybridization of the HME cDNA probe to the RT-PCR product was used to confirm the presence of HME mRNA.

In situ hybridization. Probes for in situ hybridization were generated as described (50). A cDNA fragment corresponding to HME bp 1-400, which extends through exons 1 and 2, was subcloned into a pGEM7(+) transcription vector from Promega (Madison, WI). Sense 
and antisense cRNA probes were transcribed in the presence of digoxigenin-11-UTP under conditions recommended by and with reagents from Boehringer-Mannheim (Indianapolis, IN). Paraffin-embedded tissue sections $(5 \mu \mathrm{m})$ were rehydrated to PBS and treated with proteinase $\mathrm{K}$, then rinsed in $0.1 \mathrm{M}$ triethanolamine buffer, acetylated in $0.25 \%$ acetic anhydride, and air dried. Sections were then incubated at $42^{\circ} \mathrm{C}$ with digoxigenin-labeled cRNA probes $(18 \mathrm{~h}$ in a humidified chamber). Unhybridized probe was removed by digestion with RNase A and sections were washed under stringent conditions before treatment with alkaline phosphatase-conjugated antidigoxigenin antibody and $10 \%$ normal sheep serum. 5-bromo-4-chloro-3-indoyl phosphate and nitroblue tetrazolium were used as chromogens. After development for $24 \mathrm{~h}$ in the dark, the color reaction was stopped with Milli-Q water and slides were counterstained with nuclear fast red. Sections were examined under a BX60 light microscope with a PM-30 automatic photomicrographic system from Olympus America, Inc. (Melville, NY).

Immunohistochemistry. Serial sections of aortic tissue $(5 \mu \mathrm{m})$ were deparaffinized and rehydrated to PBS. Slides were quenched with $0.3 \%$ hydrogen peroxide, treated with $0.1 \%$ trypsin $(5 \mathrm{~min}$ at $37^{\circ} \mathrm{C}$ ), then blocked with dilute horse serum (goat serum was used for sections to be stained for HME). Sections were incubated for $30 \mathrm{~h}$ at $4^{\circ} \mathrm{C}$ in a humidified chamber with the following antibodies: mouse anti-human MMP-2 (Ab-3; Calbiochem, La Jolla, CA), mouse antihuman MMP-7 (Ab-1; Calbiochem), mouse anti-human MMP-9 (Ab-3; Calbiochem), mouse anti-human CD68/KP1 for tissue macrophages (Dako Corp., Carpinteria, CA), and affinity-purified rabbit anti-HME (1:350). After incubating with biotin-conjugated horse anti-mouse $\mathrm{IgG}$ for $30 \mathrm{~min}$ at room temperature (sections treated with anti-HME were incubated with biotin-conjugated goat anti-rabbit IgG), peroxidase-conjugated avidin-biotin complex solution was applied to all sections for 30 min according to the manufacturer's instructions (Vectastain Elite kit; Vector Laboratories, Burlingame, CA). Control sections were incubated without primary antibody and then processed under identical conditions. Immune complexes were detected with diaminobenzidine (DAB) before counterstaining with hematoxylin.

For double-label immunohistochemistry, tissue sections were incubated with mouse anti-CD68, as described above, but the secondary antibody was replaced by peroxidase-conjugated horse antimouse IgG. Sections were developed with DAB substrate and then incubated with dilute goat serum for $20 \mathrm{~min}$ at room temperature. Rabbit anti-HME was applied overnight at $4^{\circ} \mathrm{C}$, followed by incubation with biotin-conjugated goat anti-rabbit IgG for $30 \mathrm{~min}$ at room temperature. Sections were incubated with alkaline phosphataseconjugated avidin-biotin complex (30 min at room temperature), and immune complexes were detected with an alkaline phosphatase substrate (Vector Laboratories). Slides were counterstained with hematoxylin.

Immunohistochemical staining was also used to determine if the anti-HME antibodies exhibited any degree of cross-reactivity with intact or damaged elastic fibers in aortic tissue. Deparaffinized sections of normal aorta were rehydrated and incubated with elastase buffer (50 mM Tris- $\mathrm{HCl}, \mathrm{pH} 7.5,150 \mathrm{mM} \mathrm{NaCl}, 10 \mathrm{mM} \mathrm{CaCl}$, and $0.02 \%$ Brij-35) containing either 0,10 , or $100 \mathrm{U} / \mathrm{ml}$ type I porcine pancreatic elastase (PPE; Sigma). Slides were incubated at $37^{\circ} \mathrm{C}$ for $1 \mathrm{~h}$ in a humidified chamber, then washed in elastase buffer and processed for immunohistochemistry with anti-HME antibodies as described above.

Elastin binding assay. Recombinant HME and murine macrophage elastase (MME) were expressed in E. coli and purified as the 22-kD active forms, as described (51). Human MMP-7 was expressed in baculovirus, purified, and activated as previously described (52). Because human MMP-2 and MMP-9 bind elastin through fibronectin type II-like repeats common to these two enzymes (52), MMP-9 was used as a representative gelatinase for these experiments. It was obtained from HT-1080 cells cotransfected with $92-\mathrm{kD}$ gelatinase cDNA and E1A to suppress endogenous MMP production, purified free of TIMP by gelatin-agarose chromatography and activated, as described (53). Human neutrophil elastase (HNE) and recombinant human TIMP-1 were purchased from Calbiochem, and PPE was obtained from Sigma. Each enzyme was independently dissolved in 100 $\mu \mathrm{l}$ of binding buffer $(50 \mathrm{mM}$ Tris- $\mathrm{HCl}, \mathrm{pH} 7.5,150 \mathrm{mM} \mathrm{NaCl}, 10 \mathrm{mM}$ $\mathrm{CaCl}_{2}$, and $0.02 \%$ Brij-35) at a concentration of $7 \times 10^{-7} \mathrm{M}$, then mixed with a molar excess of insoluble bovine elastin (ES60; Elastin Products Co.) or binding buffer alone. An equimolar concentration of TIMP-1 was added to the enzyme mixture in a subset of experiments. Enzyme mixtures were agitated for $10 \mathrm{~min}$ at $4^{\circ} \mathrm{C}$ and the insoluble elastin was precipitated by brief centrifugation. The residual elastolytic activity in the supernatant was measured by incubation with a fluorochrome-labeled elastase substrate, as described previously (54). Elastin binding was calculated as the fraction of elastolytic activity lost upon incubation with insoluble elastin compared with incubation with binding buffer alone. Results were expressed as the mean \pm SEM of six different experiments and compared using ANOVA and the Newman-Student-Keul's multiple comparisons test (48).

\section{Results}

\section{Expression of HME $m R N A$ in AAA tissues}

Using total RNA extracted from 18 aortic tissue specimens, RT-PCR was coupled with Southern analysis to detect the presence of HME-specific mRNA. As illustrated in Fig. 1, the 261-bp amplification product expected for HME was identified in all AAA and AOD tissues examined (six of six each). In contrast, HME mRNA was detectable in only one of six normal aortic tissues, perhaps due to an unrecognized area of atherosclerosis in this single specimen.

\section{HME recovered from aortic tissue extracts is enzymatically active in vitro}

Total protein extracts were prepared from 15 aortic tissue specimens for immunoblot analysis. Samples were processed

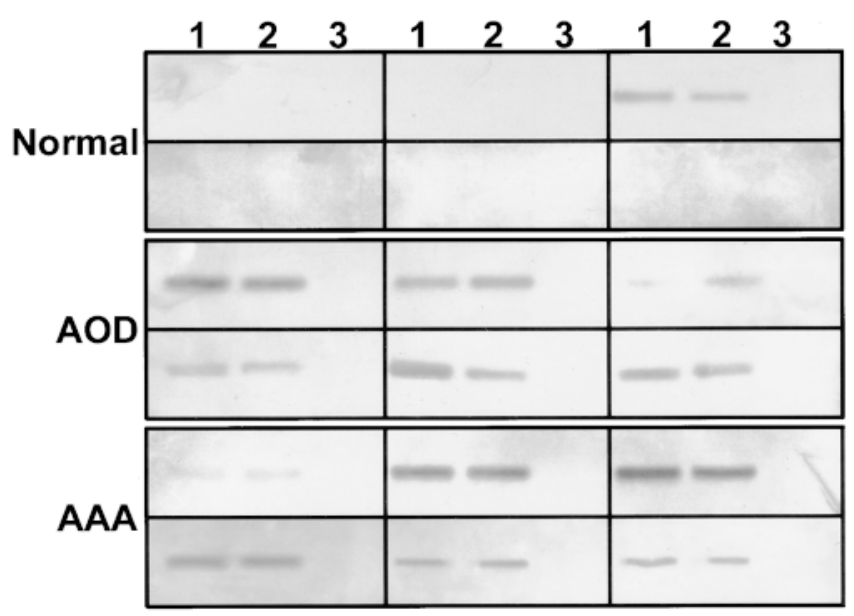

Figure 1. Expression of HME mRNA in AAA. Total RNA extracted from abdominal aortic tissue was subjected to RT-PCR using primers specific for HME (bp 663-1035) and amplification products were detected by Southern hybridization with an end-labeled oligonucleotide probe corresponding to HME bp 774-794. For each of 18 samples, lanes 1 and 2 represent duplicate reactions for HME and lane 3 represents a negative control (absence of reverse transcriptase). A 261-bp RT-PCR product corresponding to HME mRNA was reproducibly detected in all AAA and AOD samples (six of six each), but in only one of six normal aortas. 
A

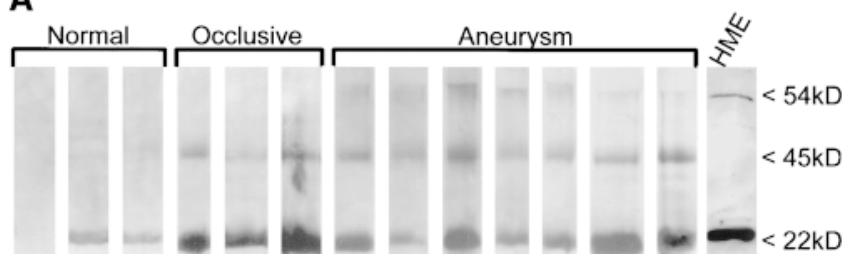

B

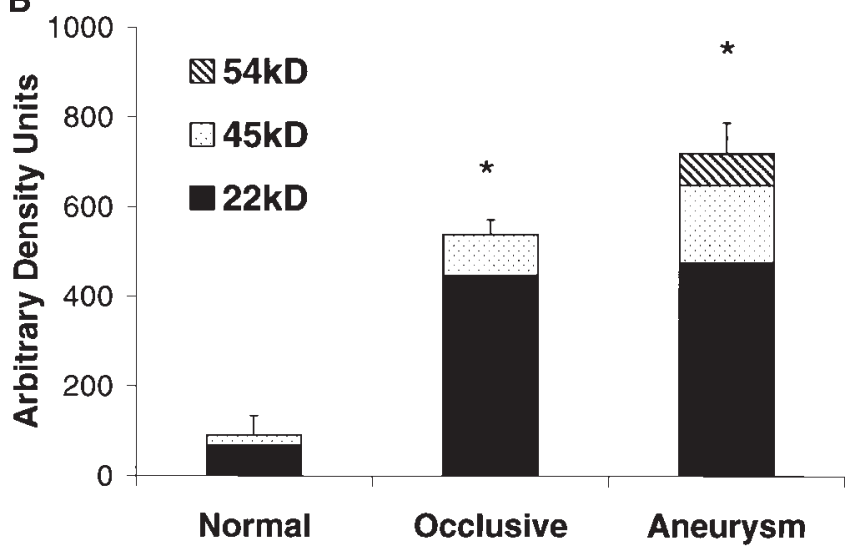

C

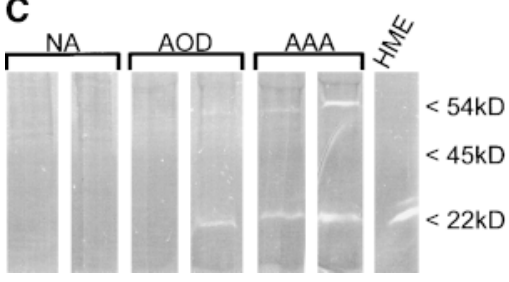

Figure 2. Immunoreactive and enzymatically active HME protein is present in AAA. $(A)$ Nondenatured extracts of abdominal aortic tissue were resolved by SDS-PAGE $(20 \mu \mathrm{g}$ total protein per lane) and transferred to nitrocellulose. Membranes were incubated with affinity-purified rabbit anti-HME antibodies and immunoreactive proteins were detected by ECL. Proteins corresponding to proHME $(54 \mathrm{kD})$, a $45-\mathrm{kD}$ intermediate product of HME processing, and the 22-kD final active form of HME are indicated. The activated form of recombinant HME is shown on the far right. $(B)$ The relative amount of immunoreactive HME protein recovered from each type of aortic tissue was measured by densitometry (mean \pm SEM; $* P<0.05$ vs. normal aorta). ( $C$ ) Aortic tissue extracts were subjected to casein substrate gel zymography and enzymatically active proteins were identified by clear bands against a dark background of intact substrate. Caseinolytic bands corresponding to $54-\mathrm{kD}$ proHME and the 22-kD active form of HME are indicated, and the activated form of recombinant HME is shown on the far right. $N A$, normal aorta. in the presence of proteinase inhibitors to prevent autocatalytic processing during extraction, and immunoblots were performed under nondenaturing conditions to permit comparison with substrate gel zymograms. Using samples normalized for total protein concentration, three immunoreactive bands were detected with affinity-purified rabbit anti-HME antibodies in seven of seven AAA specimens (Fig. $2 A$ ). The molecular masses of these proteins correspond to those expected for the latent proenzyme $(54 \mathrm{kD})$, the intermediate product of $\mathrm{HME}$ produced by carboxy-terminal processing $(45 \mathrm{kD})$, and the 22 $\mathrm{kD}$ active form of HME obtained after complete extracellular processing (39); in addition, the $22-\mathrm{kD}$ band comigrated with an activated form of recombinant HME. The 22-kD form of HME was also observed in three of three extracts of AOD and it was present in two of three normal aortas; however, proHME was not identified in either AOD or normal aorta. Overall, the total relative amount of immunoreactive HME recovered from AAA and AOD tissues was about six- to sevenfold greater than normal aorta by densitometric analysis, but there was no significant difference between AAA and AOD tissues

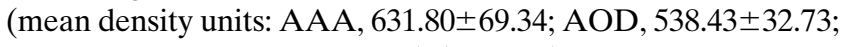
and normal aorta, 91.02 \pm 42.77 ) (Fig. 2 B).

Aortic tissue extracts were examined by $\alpha$-casein substrate gel zymography to determine if the HME detected in AAA tissue was capable of enzymatic activity in vitro. Extracts prepared in the presence of EDTA were used for substrate zymography, because extraction in the absence of metal chelators led to degradation and loss of enzymatic activity (data not shown). AAA extracts contained prominent caseinolytic activities migrating at 54 and $22 \mathrm{kD}$, corresponding to the proenzyme and fully activated forms of HME (Fig. $2 C$ ). Although the 45-kD intermediate form of HME observed by immunoblotting did not appear to be enzymatically active under the conditions used here, this may have been due to further auto- processing during sample preparation. It is also possible that the $45-\mathrm{kD}$ immunoreactive band represented a nondissociable complex between TIMP-1 (25 kD) and the 22-kD activated form of HME, but this was not specifically examined. Whereas AOD extracts also contained the $22-\mathrm{kD}$ caseinolytic activity attributable to the active form of HME, no casein-degrading activities were detected in extracts of normal aorta.

\section{Production of HME is localized to tissue macrophages in AAA tissue}

In situ hybridization was used to examine the expression and cellular localization of HME in aortic tissues. Fig. 3 demonstrates that HME mRNA was actively expressed in AAA tissue and that it was localized to macrophage-like cells within the degenerative media. Although HME mRNA was also expressed by intimal plaque macrophages in AOD (data not shown), expression of this enzyme was undetectable within the elastic media in either AOD or in normal aorta (data not shown). The localization of HME to aneurysm-infiltrating macrophages was further confirmed by immunohistochemistry, in which sections were simultaneously stained with antibodies recognizing either HME or CD68. As shown in Fig. 4, HME was frequently detected in association with CD68-positive macrophages and it often localized to adjacent elastin fiber fragments within the degenerative media. Therefore, the cellular expression of HME in aneurysm tissue is superficially similar to that observed previously for $92-\mathrm{kD}$ gelatinase (32).

The histopathology of $A A A$ exhibits regional heterogeneity with three distinct regions

To examine the regional heterogeneity of MMP expression in AAA in more detail, histochemical staining for elastin was coupled with immunohistochemistry for macrophages and each of four MMPs that might participate in aortic elastin deg- 


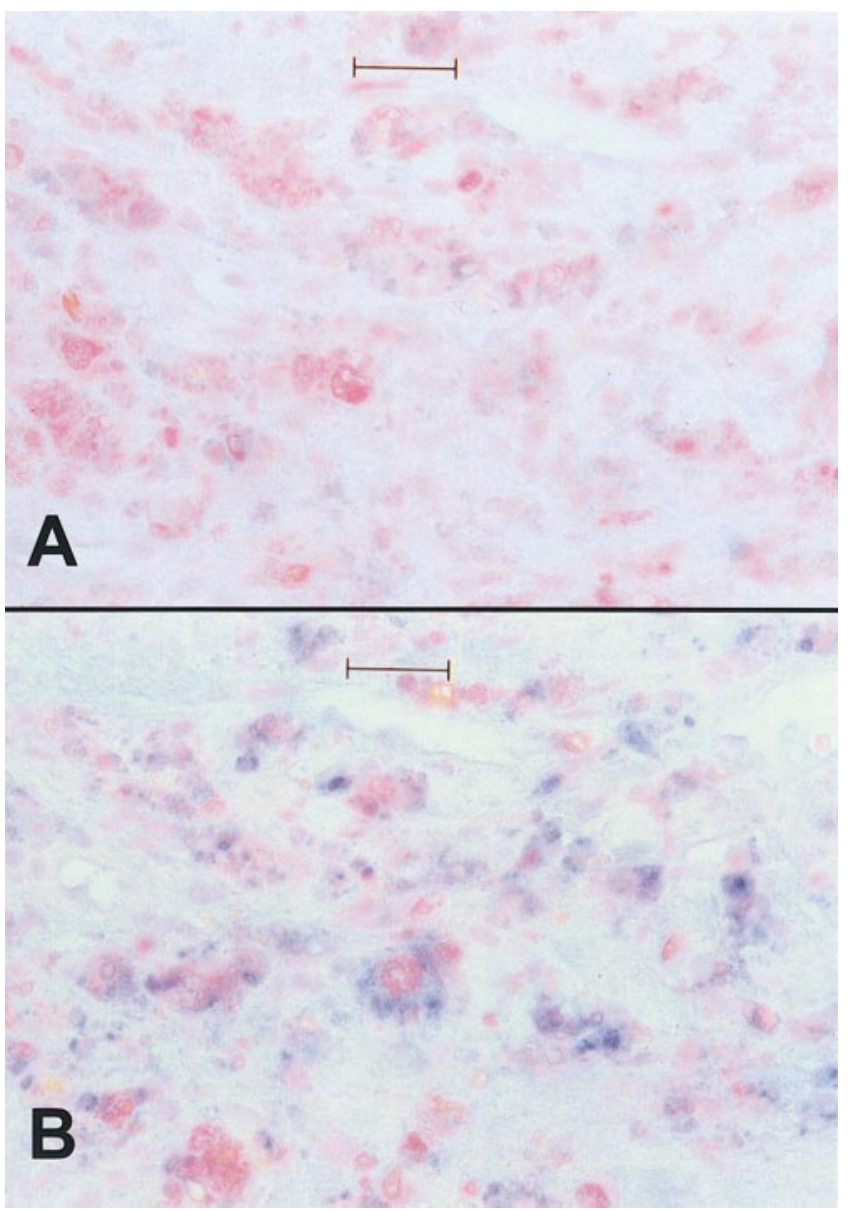

Figure 3. In situ expression of HME mRNA in AAA. Digoxigeninlabeled cRNA probes were transcribed from an HME plasmid construct and hybridized with formalin-fixed serial sections of AAA tissue. After treatment with RNase A and stringent washing conditions, sections were incubated with alkaline phosphatase-conjugated antidigoxigenin antibodies. 5-Bromo-4-chloro-3-indoyl phosphate and nitroblue tetrazolium were used as chromogens to yield a dark blue reaction product, and sections were counterstained with nuclear fast red. (A) Hybridization with sense cRNA for HME (negative control). $(B)$ Serial section of tissue shown in $A$, hybridized with antisense cRNA for HME. Scale bar, $40 \mu \mathrm{m}$.

radation. As shown in Fig. 5, specimens of normal aorta demonstrated minimal intimal thickening and an elastic media composed of mature undamaged lamellae, in which layers of elastin fibers alternated with layers of spindle-shaped vascular smooth muscle cells. No inflammatory infiltrates were seen in the media and none of the four elastolytic MMPs were detected by immunohistochemistry. Although CD68-positive mononuclear phagocytes were present in some sections of normal aorta, they were restricted to the adventitia or to small areas of minor intimal thickening.

Specimens of AOD demonstrated calcific intimal atherosclerosis and grade III-IV lipid-laden plaques with periodic fracturing. Fig. 5 shows that the lamellar structure of the elastic media was well preserved in the majority of AOD specimens and that inflammatory cell infiltrates were confined to the intima. As expected, a significant number of differentiated tissue macrophages was seen within the thickened intima of AOD,

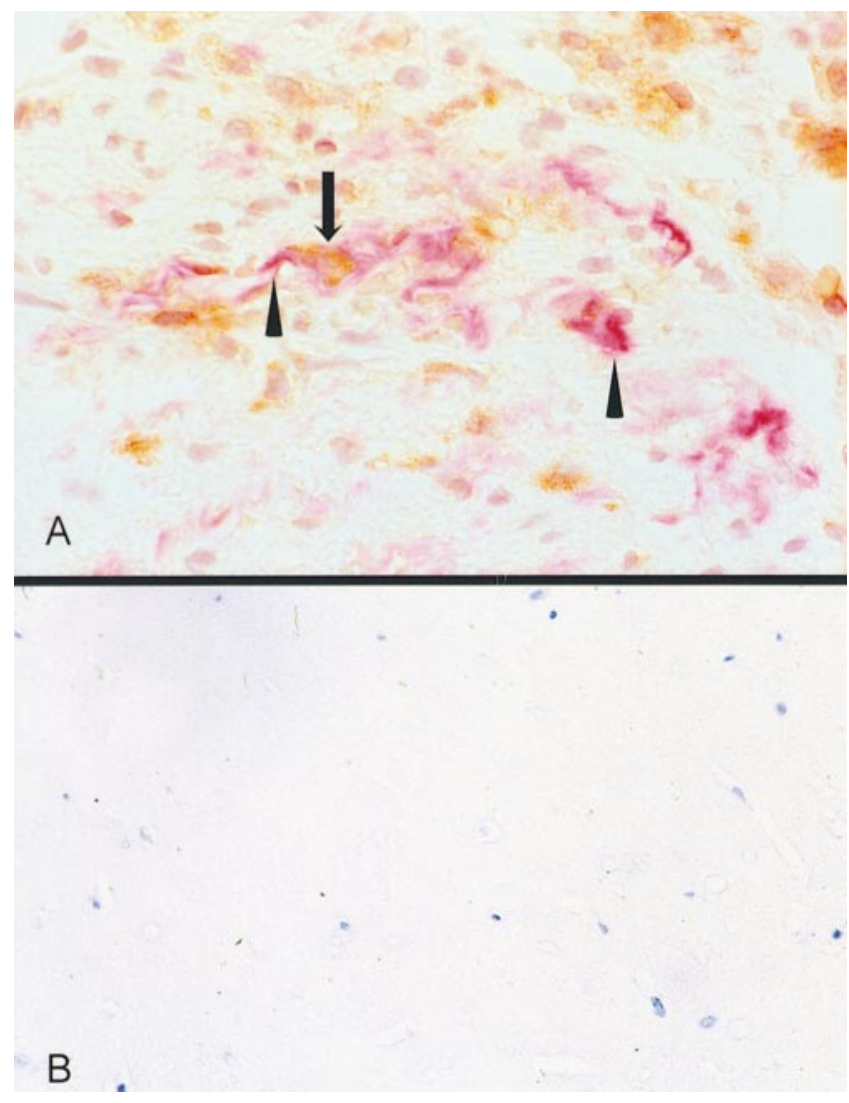

Figure 4. Colocalization of HME and tissue macrophages in aneurysmal aorta. $(A)$ Formalin-fixed sections of AAA tissue were incubated with mouse anti-human CD68 (recognizing macrophages), followed by peroxidase-conjugated secondary antibodies and $\mathrm{DAB}$ to yield a brown reaction product. HME was then detected in the same sections using rabbit anti-HME antibodies, followed by biotin-conjugated secondary antibodies, an avidin-biotin-alkaline phosphatase conjugate, and an alkaline phosphatase substrate which forms a red precipitate. CD68-expressing macrophages staining brown (arrow) are colocalized with HME (red). The arrowheads indicate the localization of HME to residual medial elastic fibers in close spatial relationship to HME-expressing macrophages. $(B)$ Section of tissue shown in $A$ to which no primary antibodies were applied before processing for immunohistochemical staining (negative control).

some of which were positive for MMP-2 and MMP-9 (data not shown). As previously reported (45), focal areas in the shoulder regions of the plaque were positive for both HME and MMP-7 (data not shown). Nonetheless, the medial layer demonstrated no significant inflammatory infiltrates or any cells immunoreactive for elastolytic MMPs.

In accord with previous investigations, AAA specimens exhibited severe intimal atherosclerosis and an amorphous media containing few intact elastic lamellae. These areas of the media were generally hypocellular, with abnormally shaped smooth muscle cells, fibroblasts, and occasional macrophages, although other areas of the media exhibited concentrated infiltrates of mononuclear inflammatory cells. All four elastolytic MMPs were identified at some point within the degenerative media of AAA (matrilysin was only rarely detected) and yet, despite the frequent presence of MMP-2, MMP-9, and HME, the distribution of these enzymes within the aneurysmal media was not uniform. Thus, three distinct regions of the aneurysm 


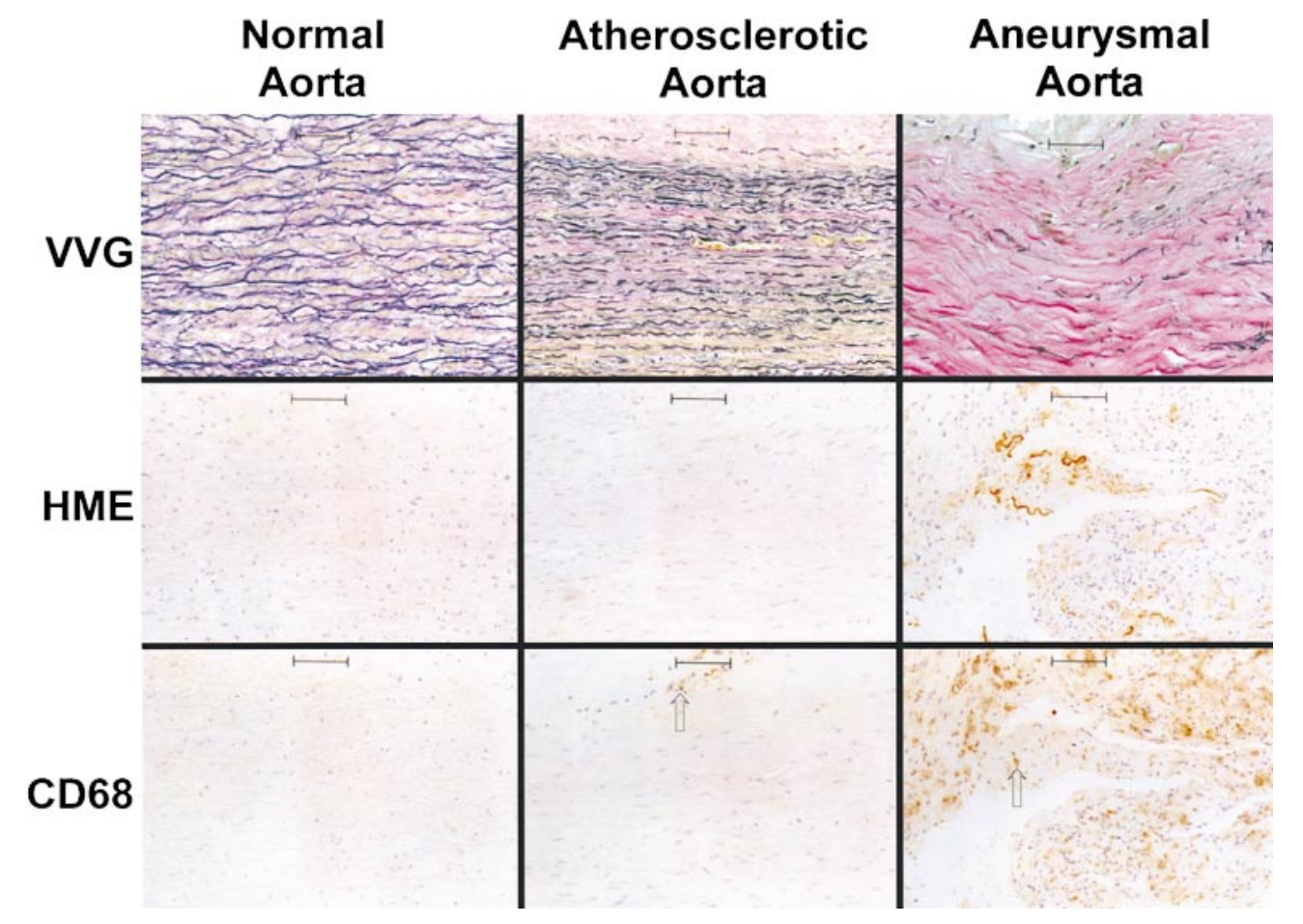

Figure 5. Histopathology and immunohistochemistry of normal and diseased aortic tissues. Formalin-fixed serial sections of normal, atherosclerotic, and aneurysmal abdominal aorta were stained with Verhoeff-Von Gieson elastin ( $V V G, t o p)$, as well as immunohistochemical techniques for HME (middle) and macrophages (CD68, bottom) Immune complexes were detected with $\mathrm{DAB}$ as a brown reaction product. VVG staining discloses the destruction of the medial elastic lamellae in aneurysmal aorta and their preservation in atherosclerotic aorta. Although only intimal macrophages are seen in atherosclerotic tissue (arrows), aneurysmal tissue also exhibits the localization of HME to residual elastic fibers and a significant number of macrophages (arrows) within the degenerative elastic media. Scale bar, $80 \mu \mathrm{m}$.

wall were characterized based on cellular, histochemical, and immunohistochemical appearance, in order to provide a better framework for examining the heterogeneous localization of elastolytic MMPs in AAA. The features of these three regions are summarized in Table I.

Amorphous media (Fig. 6). The majority of the aneurysm wall was characterized by relatively nondescript amorphous tissue, with a sparse population of cells surrounded by an abundance of fibrocollagenous extracellular matrix. The absence of elastic lamellae or even elastic fiber fragments was particularly striking. Because these regions were predominantly subintimal and because the internal elastic lamina was typically absent in AAA, it was often difficult to discern a clear transition from the atherosclerotic intima to the amorphous media. Like the base of many atherosclerotic plaques, however, neovascularization and scattered mononuclear phagocytes were prominent in this area of the aneurysm wall. By immunohistochemical staining of serial sections, the amorphous media contained cells positive for MMP-2, MMP-9, and HME, somewhat similar to that seen in atherosclerotic plaque, but

Table I. Microscopic Subclassification of Regional Heterogeneity within AAA Tissues

\begin{tabular}{llll}
\hline & & Region of aneurysm wall \\
\cline { 4 - 4 } \multicolumn{1}{c}{ Tissue characteristics } & Inflammatory media & Amorphous media & Active media \\
\hline Extracellular matrix & & & Fragmentary \\
$\quad$ Elastin & None apparent & None apparent & Sparse \\
Collagen & None apparent & Moderately dense & Moderate \\
Cellular composition & & & Moderate \\
Smooth muscle cells & None apparent & Sparse & Mild \\
Mononuclear phagocytes & Dense infiltrates & Mild & Mild \\
Lymphocytes & Dense infiltrates & Moderate & Mild \\
Fibroblasts & None apparent & Moderately dense & 0 \\
Endothelial cells & Moderately dense & & 0 \\
MMP expression* & & $++($ SMC, Fb, MPh $)$ & $+($ Rare $)$ \\
MMP-2 (gelatinase A) & 0 & $++(\mathrm{MPh})$ & $++(\mathrm{MPh})^{\ddagger}$ \\
MMP-7 (matrilysin) & 0 & $++(\mathrm{MPh})$ & \\
MMP-9 (gelatinase B) & $++(\mathrm{MPh})$ & 0 & \\
MMP-12 (HME) & & & 0 \\
\hline
\end{tabular}

$*$ MMP expression was detected by immunohistochemistry and graded on the following scale: 0 (undetectable), $+(<25 \%$ of cells positive $),++(25-$ $50 \%$ of cells positive $)$, and $+++(>50 \%$ of cells positive $)$, with cell types indicated in parentheses. ${ }^{\ddagger}$ Prominent immunolocalization to elastic fiber fragments. $S M C$, vascular smooth muscle cells; $F b$, fibroblasts; $M P h$, mononuclear phagocytes. 


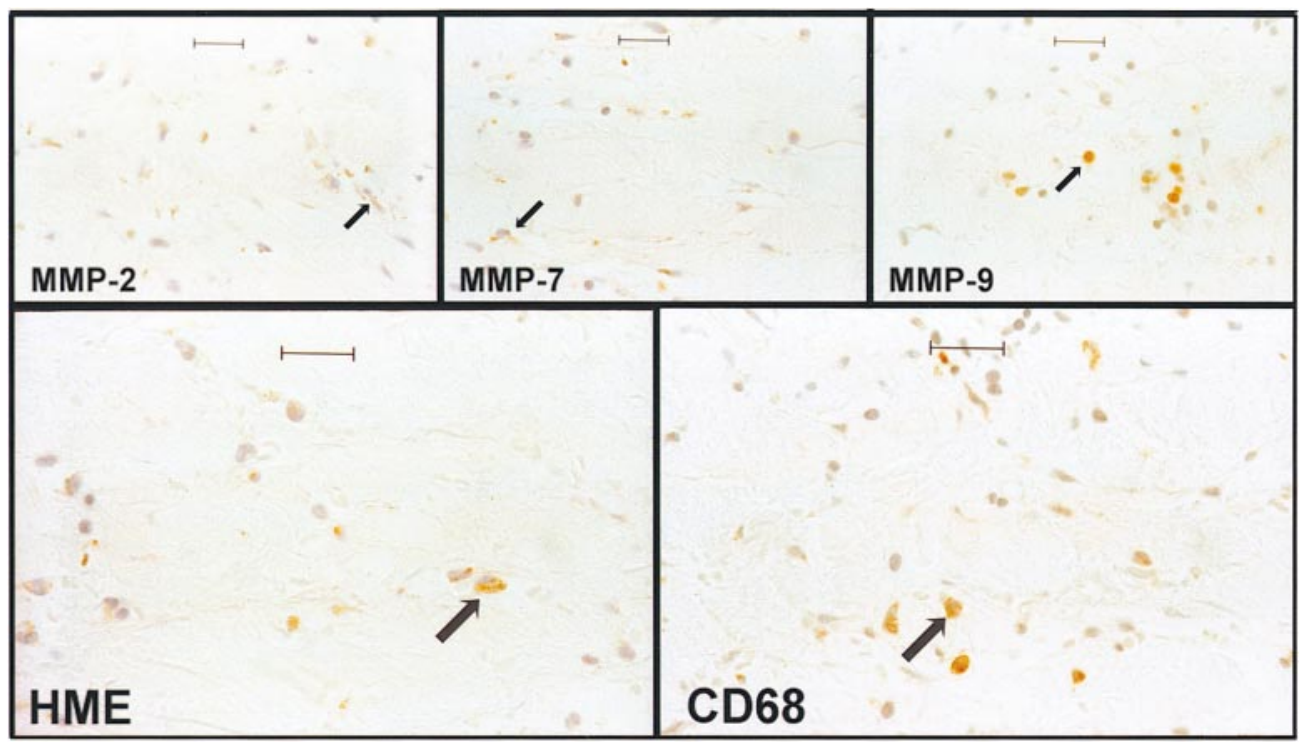

Figure 6. Immunohistochemical localization of MMPs in AAA: amorphous media. Five consecutive serial sections of AAA tissue were stained by immunohistochemical techniques using antibodies specific for HME, CD68, MMP-2, MMP-7, and MMP-9. Immune complexes were detected by immunoperoxidase as a brown reaction product and sections were counterstained with hematoxylin. The amorphous degenerative media contains scattered CD68-positive macrophages, which sporadically express all of the elastolytic MMPs examined (arrows). Scale bar, $30 \mu \mathrm{m}$. few of these cells stained positively for matrilysin. Most of the MMP-positive cells were identified as tissue macrophages based on their coexpression of CD68 antigen.

Active media (Fig. 7). At irregular points within the amorphous media there were areas displaying an increase in spindle-shaped cells and scattered, birefringent, elastic fiber remnants. Because these regions may be sites of ongoing elastin degradation, they were defined as the active media. On immunohistochemical grounds, these areas were distinguished from the amorphous media by the presence of many CD68-positive cells which were also positive for HME. The lack of MMP-9 or MMP-2 positive cells in the active media was also a remarkable feature of these areas. Most striking, however, was that in the active media the anti-HME antibody uniformly and specifically recognized residual elastic fiber fragments. On serial sections, these same elastin fragments were spatially associated with CD68-positive cells, and double immunohistochemical staining confirmed the cellular localization of HME to macrophages (Fig. 4).
Chronic inflammatory media (Fig. 8). A third area characteristic of AAA tissues consisted of areas with tightly packed mononuclear cells, primarily tissue macrophages and lymphocytes. These inflammatory infiltrates occurred sporadically at all levels within the aortic wall, but they were more frequent on the adventitial side of the media. Fig. 8 shows the results of immunohistochemical stains applied to serial sections through a representative area of chronic inflammatory media in an aortic aneurysm. The only proteinase substantially and consistently identified in this area was MMP-9. On serial sections, a similar subset of cells was identified as infiltrating tissue macrophages by CD68 expression.

\section{The proximal transition zone of $A A A$ exhibits morphological features of the active media}

Several specimens of AAA tissue were obtained from the longitudinal transition zone between the grossly normal proximal infrarenal aorta and the aneurysm itself. Although these areas exhibited relatively intact elastic lamellae within the media

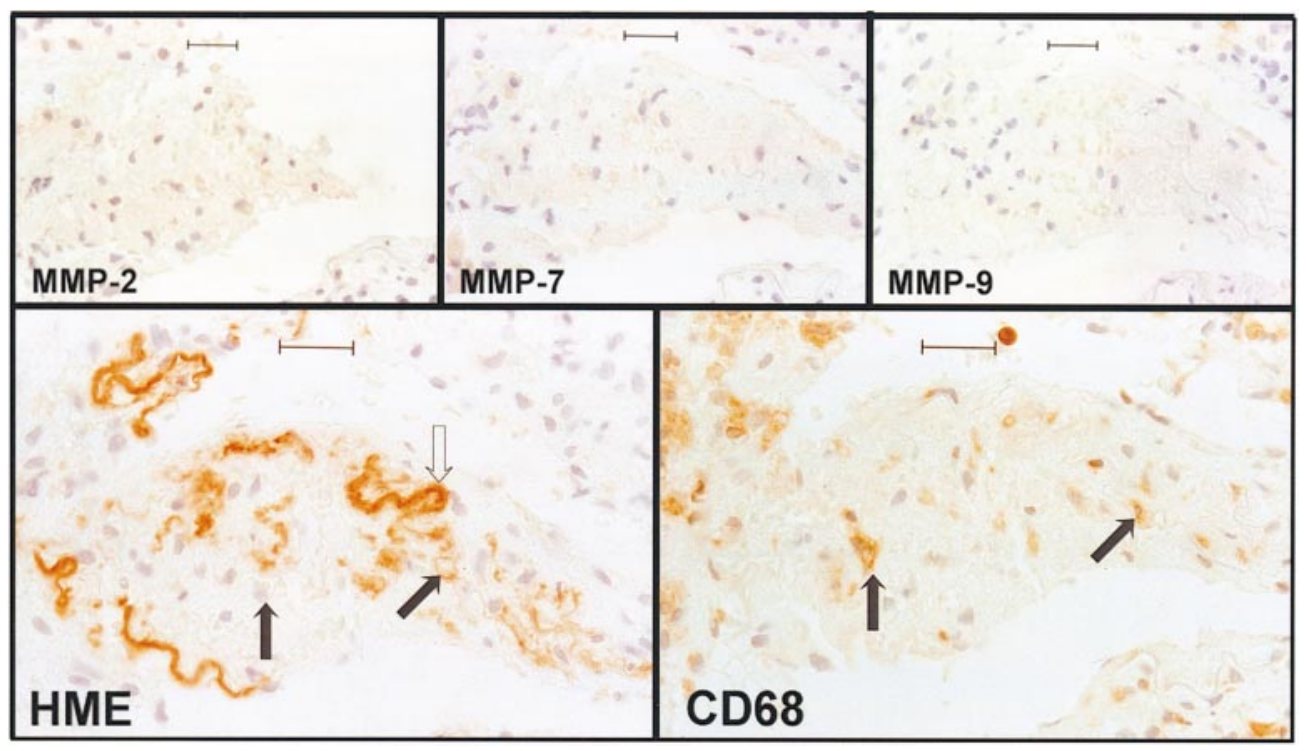

Figure 7. Immunohistochemical localization of MMPs in AAA: active media. A second area of AAA tissue is depicted in five consecutive serial sections stained by immunoperoxidase techniques (brown reaction product). This active area of the degenerative media was notable for the presence of residual elastic fiber fragments and CD68positive macrophages. HME was the predominant enzyme produced in these areas, where it was localized to macrophages (solid arrows) in close apposition to fragmented elastin. HME was also prominently localized to residual elastin fiber fragments themselves (open arrows). Scale bar, $30 \mu \mathrm{m}$. 


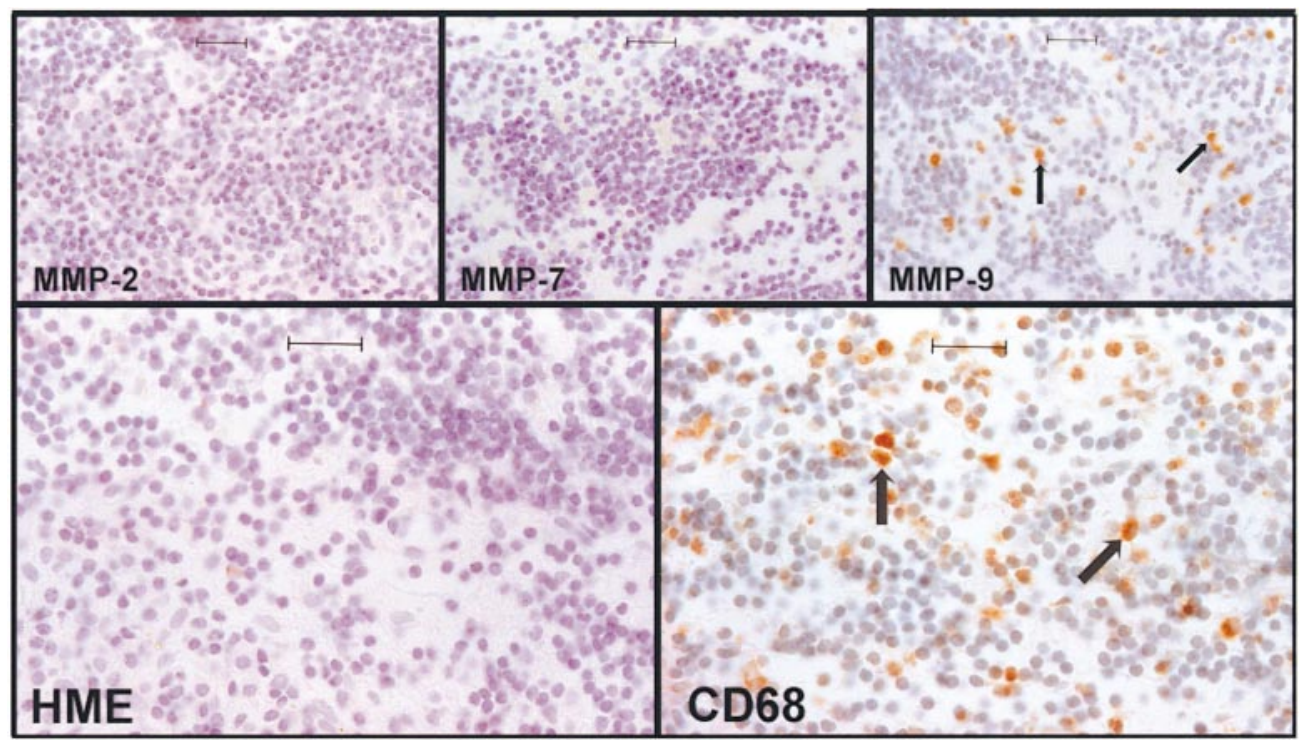

Figure 8. Immunohistochemical localization of MMPs in AAA: inflammatory media. A third area of AAA tissue is depicted in five consecutive serial sections stained by immunoperoxidase techniques (brown reaction product). These areas of the degenerative media are dominated by dense mononuclear inflammatory cell infiltrates. CD68positive macrophages appear to colocalize with MMP-9 in these infiltrates (arrows), but HME and other elastolytic MMPs are not detected by immunostaining. Scale bar, $30 \mu \mathrm{m}$. and only minimal inflammatory infiltrates, immunohistochemistry revealed an abundance of HME (Fig. 9). Like the active media described above, HME was prominently localized to elastic fibers in these areas. Indeed, staining for HME provided a particularly clear distinction of the transition zone between normal aorta and the diseased aneurysmal segment.

\section{$H M E$ antibody does not cross-react with elastic fiber components or with damaged elastin}

Because the immunolocalization of HME to elastic fibers was a particularly important observation, it was necessary to confirm the in vitro specificity of the antibodies used in this study. Therefore, additional immunoblot assays were performed with several different types of elastin, two biologically active elastin-derived peptides, and type IV collagen, as well as recombinant HME protein. Affinity-purified antibodies raised to the amino-terminal HME peptide did not recognize any of these other proteins, although they bound with high affinity to authentic HME as expected (data not shown). To further examine the specificity of these antibodies in whole tissue, sections of normal aorta were incubated with pancreatic elastase before immunohistochemical staining for HME. Despite significant damage to the medial elastin as identified by light microscopy, there was no apparent binding of anti-HME to the residual elastic fiber fragments (data not shown).

\section{Insoluble elastin binds macrophage elastase with high affinity}

To test the possibility that HME might bind to elastic fibers with a higher degree of affinity than other elastolytic proteinases present in AAA tissues, recombinant forms of HME and MME were compared with the purified active forms of several other elastolytic enzymes using an in vitro binding assay. The elastolytic activities of MMP-12, MMP-9, HNE, and PPE were all sequestered with high affinity by insoluble elastin. Importantly, HME and MME exhibited the highest fractional binding of the enzymes examined under these assay conditions, with nearly all of their enzymatic activity bound by elastin (94.0 \pm 6.0 and $96.1 \pm 2.9 \%$, respectively). This compared with only $53.7 \pm 13.6 \%$ for MMP-9 and $20.1 \pm 16.6 \%$ for MMP-7 (each $P<0.05$ vs. HME). Although the overall amount of elastase activity was substantially higher for HNE and PPE compared with the other enzymes tested (data not shown), the fractional binding of these serine proteases was also significantly less than that of either HME or MME (HNE, $71.4 \pm 7.3 \%$; PPE, $57.1 \pm 4.4 \%$; each $P<0.05$ vs. HME). In further experiments to determine if TIMPs might prevent MMP12 from binding to insoluble elastin, the addition of TIMP-1 had only a minor effect on the elastin binding ability of MME (a decrease in fractional binding from $96.1 \pm 2.9$ to $81.2 \pm 10.5 \%$; $P>0.05)$. These in vitro data thereby correspond to the observations in AAA tissue, where HME appears to be capable of sustained binding to elastic fiber fragments. They also help explain why this enzyme is detectable in association with elastin fibers in AAA, whereas other elastases produced in the same tissue environment do not exhibit this immunohistochemical pattern.

\section{Discussion}

HME is a recently described homologue of MME, a 22-kD metalloproteinase first isolated from murine peritoneal macrophage conditioned medium $(39,50,55)$. Although not normally expressed in adult human tissues, HME has been identified by immunohistochemistry and in situ hybridization in tissues undergoing active remodeling, such as the term placenta (50). Peripheral blood monocytes do not possess HME protein or mRNA, yet macrophage elastase accounts for at least half the elastolytic activity secreted by human alveolar macrophages obtained from cigarette smokers (39). This indicates that macrophage expression of HME may have an important role in pulmonary emphysema and other degenerative disorders associated with elastin degradation. In testing this hypothesis in genetically altered mice, Shipley and colleagues found that MMP-12 is essential for macrophage-mediated proteolysis and matrix invasion in vitro (56). Furthermore, mice with targeted deletions of MME exhibit a marked reduction in pulmonary elastin degradation and emphysema induced by in vivo exposure to cigarette smoke (57). MMP-12 is also expressed in animal models of atherosclerosis, where it is localized to foamy macrophages in aortic lesions of both cholesterol-fed rabbits (46) and apo E-deficient mice (47). 


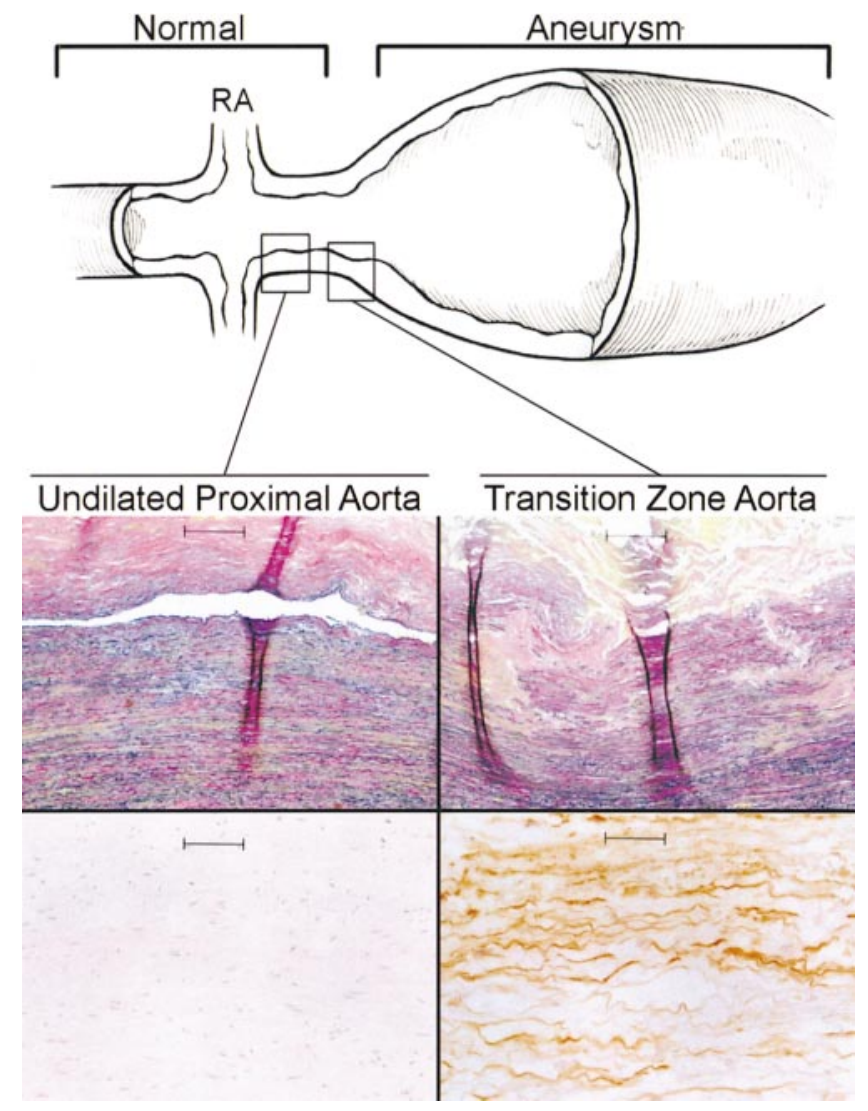

Figure 9. Immunolocalization of HME in the proximal transition zone of AAA. Schematic diagram depicting the location of proximal transition zone specimens obtained from patients with AAA (top). Tissue sections taken from the uninvolved proximal aorta and the adjacent transition zone were stained with VVG (middle) and by immunohistochemical techniques for HME antibodies (bottom). HMEspecific immune complexes were detected by immunoperoxidase to reveal a brown reaction product. HME is not observed in the undilated proximal aorta but is readily apparent in the transition zone. The localization of HME to elastic fibers in the proximal-most aspect of the aneurysm is similar to that seen in the active media of the aneurysmal aorta (Fig. 7), but it appears even more prominent due to the greater amount of elastin present. Scale bar, $40 \mu \mathrm{m}$.

Importantly, transgenic mice with homozygous deficiencies in both apo E and urokinase-type plasminogen activator (u-PA) exhibit a reduction in hypercholesterolemia-induced microaneurysm formation, an effect apparently due to diminished activation of proMME in the absence of u-PA (47).

Extensive remodeling of the extracellular matrix plays a critical role in the development, progression, and rupture of AAA, and it has long been suspected that aneurysmal degeneration is mediated by one or more proteinases specifically capable of degrading insoluble elastin. Macrophage elastase is one of four mammalian MMPs with the capacity to degrade elastin in vitro, and we have demonstrated here for the first time that human AAA tissues actively express HME in vivo. As might have been expected, HME expression was localized to aneurysm-infiltrating macrophages within the degenerative media of AAA and, like previous studies, neither MMP-2, MMP-9, nor HME was observed within the elastic media of either normal aorta or AOD tissues. These findings support the view that localized expression of elastolytic MMPs at the site of aortic tissue damage plays an important role in the pathobiology of aortic aneurysm disease and they place new emphasis on the participation of HME in this process.

Earlier studies from our laboratory have demonstrated that MMP-9 and MMP-2 are the most prominent elastase activities secreted by human AAA tissues in short-term organ culture (32). Although elastolytic activity corresponding to HME was not detected in aortic tissue conditioned medium, these experiments demonstrate that substantially greater amounts of HME are present in AAA tissue than normal aorta. We have also shown that HME binds with high affinity to elastin fibers, both in vitro and in vivo. Therefore, it appears likely that immunoreactive and enzymatically active forms of HME are readily sequestered within elastin-rich tissues, perhaps to a greater extent than other MMPs. More vigorous extraction of aortic tissue proteins may account for the improved recovery of HME in this study as compared with previous investigations using aortic conditioned media alone.

The most intriguing observation revealed by this study was the prominent and specific immunolocalization of HME to elastic fiber fragments within selected regions of the degenerative aortic media. Because this suggested that HME is found in association with a matrix substrate potentially relevant in the pathogenesis of AAA, the specificity of the antibody for HME was confirmed by a series of control experiments to exclude inadvertent cross-reactivity with either elastin fiber components or damaged elastic fibers. Using immunohistochemical techniques identical to those used to detect HME in AAA, for example, no reactivity of the antibody with intact elastin fibers was observed in normal aorta, occlusive atherosclerosis, or the proximal aspect of the transition zone in AAA. Furthermore, neither intact soluble elastin nor multiple elastin-derived peptides bound the antibody in in vitro binding assays. Finally, elastase-induced injury of normal aortic tissue sections did not induce antibody binding to the residual damaged elastin. Taken together, these results support the conclusion that the unique pattern of immunoreactivity represents the specific and authentic localization of HME to residual elastic fibers in selected regions of AAA tissue. This novel finding has important implications for the unique role that HME might play in the pathogenesis of aneurysm disease.

We postulated that the localization of HME to residual elastic fibers in AAA might reflect a particularly high binding affinity of HME for elastin, especially relative to other elastolytic enzymes present in human AAA tissues. Although the structures conferring elastolytic activity upon 92 -and $72-\mathrm{kD}$ gelatinase are known to reside within three fibronectin type II-like repeats inserted in tandem with their catalytic domains, these domains are not present in matrilysin or the fully processed $(22-\mathrm{kD})$ forms of macrophage elastase (52). Indeed, processed forms of $\mathrm{HME}$ and $\mathrm{MME}$ found in tissue generally possess only the zinc-binding catalytic domain characteristic of the MMP family, which must thereby confer both substrate binding and elastolytic specificity. Furthermore, recent studies indicate that macrophage elastases exhibit important differences compared with MMP-9 and serine elastases with respect to peptide bond preferences during the degradation of insoluble elastin (58). Using in vitro binding assays with HME and MME, we found that nearly all of the active MMP-12 is rapidly sequestered upon incubation with an excess of insoluble elastin, and that this was not significantly diminished in the pres- 
ence of TIMP-1. In addition, the fractional binding of HME was two- to fivefold greater than that measured with either MMP-9 or MMP-7, respectively, and it even exceeded that obtained with the potent serine proteases, neutrophil and pancreatic elastase. Based on these findings, we speculate that the high binding affinity of HME may explain its potent elastolytic activity and its unique localization to elastic fibers in vivo. The avidity of HME for elastic fibers may also result in more sustained elastolytic activity compared with that produced by other elastases, although it is notable that binding to insoluble elastin may also promote the activation of other proMMPs (59). These findings imply that in the complex milieu of proteinases and proteinase inhibitors that characterizes human aneurysm tissues, greater tissue damage might result from local production of HME than other elastolytic enzymes. As the assays reported here were limited to a specific set of experimental conditions, further studies will be required to examine the kinetics involved in HME-elastin binding and to elucidate the structural elements responsible for this interaction.

Consistent with earlier findings, we detected MMP-2 and MMP-9 within the media of AAA by immunohistochemistry, although neither of these proteinases was found in the elastic media of AOD tissues or normal aorta. In contrast to previous studies, however, we also obtained more detailed localization of these enzymes within different regions of the aneurysm wall. The distribution of these MMPs may offer additional clues to the relative importance of these enzymes in the process of medial remodeling. Furthermore, we predict that the morphological patterns of MMP expression in different areas of the aneurysm wall might also reflect regional heterogeneity in the cell-specific regulation of various MMP genes (50).

In describing several different regions within AAA tissue, we defined one particular morphological pattern as the active media. These areas, containing fragmented elastin fibers, appeared to represent locations where elastic lamellae were subjected to aggressive degradation. The prominent expression and immunolocalization of HME in these areas suggests a key role in this aspect of medial degeneration. In support of this view, several unusually valuable aortic wall specimens were also obtained during the course of this study, encompassing the longitudinal transition zone between the normal caliber aorta and the proximal aspect of aneurysmal dilatation. Although such specimens are difficult to obtain during the routine conduct of surgical operations for AAA, they are particularly informative in that they represent areas where the process of aneurysmal degeneration might be observed in its earliest stages. Indeed, a gradient of histopathologic changes was observed along the axial length of these transition zone specimens, extending from normal aortic structure to the typical appearance of end-stage AAA. The interface of the normal and dilated aorta showed evidence of early elastin fragmentation with HME prominently localized to nearly all of the medial elastic fibers. The localization of HME indicates that it is not only present in these areas, but that it remains bound to the elastin substrate in regions where ongoing elastin degradation is expected to be the most active. Therefore, these findings lend additional support to the view that HME plays a unique role in the evolution and progression of aneurysmal degeneration.

The elevated local production of HME in AAA tissues and its distinct localization to residual elastic fiber fragments provide the strongest evidence to date that MMPs participate in aortic elastin degradation. Furthermore, these findings implicate a more central role for HME than other elastolytic MMPs in aneurysm disease. At a functional level, questions that remain to be addressed include the degree to which HME is enzymatically active in situ, how it might interact with naturally occurring proteinase inhibitors within the aneurysmal aortic wall, and whether HME is necessary and/or sufficient for the development of AAA in vivo. Studies in animal models of AAA will be particularly helpful in examining these issues. Although it remains likely that MMP-2, MMP-9, and other proteinases also participate in the development and progression of AAA, their relative contributions will need to be reassessed in light of the elevated production and novel tissue distribution of HME in aneurysm tissue.

\section{Acknowledgments}

The authors are grateful to the vascular surgery and transplant services at Barnes-Jewish Hospital for help in procuring appropriate tissue specimens, and to Jill Roby, Teresa Tolley, Bill Wester, and Catherine Flizsar for technical assistance. Drs. Howard G. Welgus, Robert P. Mecham, Robert M. Senior, and William C. Parks provided helpful discussions and critical reviews of the manuscript.

This study was supported by National Institutes of Health (NIH) grant R29 HL56701 from the National Heart, Lung, and Blood Institute, a Research Grant-in-Aid from the American Heart Association, Missouri Affiliate, and the Wylie Scholar Award from the Pacific Vascular Research Foundation, San Francisco, CA (Robert W. Thompson). John A. Curci was supported by an NIH Institutional Training Grant in Cardiovascular Surgery (T32 HL07776) and Steven D. Shapiro was supported by NIH grant R01 HL50472.

\section{References}

1. Lederle, F.A., G.R. Johnson, S.E. Wilson, E.P. Chute, F.N. Littooy, D. Bandyk, W.C. Krupski, G.W. Barone, C.W. Acher, and D.J. Ballard. 1997. Prevalence and associations of abdominal aortic aneurysm detected through screening. Aneurysm Detection and Management (ADAM) Veterans Affairs Cooperative Study Group. Ann. Intern. Med. 126:441-449.

2. Alcorn, H.G., S.K. Wolfson, Jr., K. Sutton-Tyrrell, L.H. Kuller, and D. O'Leary. 1996. Risk factors for abdominal aortic aneurysms in older adults enrolled in The Cardiovascular Health Study. Arterioscler. Thromb. Vasc. Biol. 16:963-970.

3. Cole, C.W., G.B. Hill, J. Lindsay, W.P. Mickelson, C. Mills, and D.T. Wigle. 1994. Proceedings of the workshop on the control of abdominal aortic aneurysm. Chronic Dis. Can. 15(Suppl.):S1-S64.

4. Mitchell, M.B., R.B. Rutherford, and W.C. Krupski. 1995. Infrarenal aortic aneurysms. In Vascular Surgery. R.B. Rutherford, editor. W.B. Saunders, Philadelphia. 1032-1060.

5. Tilson, M.D., and M.R. Seashore. 1984. Fifty families with abdominal aortic aneurysms in two or more first-order relatives. Am. J. Surg. 147:551-553.

6. Origuchi, N., H. Shigematsu, T. Hatakeyama, M. Nunokawa, H. Yasuhara, and T. Muto. 1996. A clinicopathological study of familial abdominal aortic aneurysms. Int. Angiol. 15:26-32.

7. Verloes, A., N. Sakalihasan, L. Koulischer, and R. Limet. 1995. Aneurysms of the abdominal aorta: familial and genetic aspects in three hundred thirteen pedigrees. J. Vasc. Surg. 21:646-655.

8. Kuivaniemi, H., G. Tromp, and D.J. Prockop. 1991. Genetic causes of aortic aneurysms. Unlearning at least part of what the textbooks say. J. Clin. Invest. 88:1441-1444.

9. Tromp, G., Y. Wu, D.J. Prockop, S.L. Madhatheri, C. Kleinert, J.J. Earley, J. Zhuang, O. Norrgard, R.C. Darling, W.M. Abbott, et al. 1993. Sequencing of cDNA from 50 unrelated patients reveals that mutations in the triple-helical domain of type III procollagen are an infrequent cause of aortic aneurysms. $J$. Clin. Invest. 91:2539-2545.

10. Kuivaniemi, H., S.J. Watton, S.J. Price, Y. Zhu, Z. Gatalica, and G. Tromp. 1996. Candidate genes for abdominal aortic aneurysms. Ann. NY Acad. Sci. 800:186-197.

11. Shah, P.K. 1997. Inflammation, metalloproteinases, and increased proteolysis: an emerging pathophysiological paradigm in aortic aneurysm. Circulation. 96:2115-2117.

12. Grange, J.J., V. Davis, and B.T. Baxter. 1997. Pathogenesis of abdomi- 
nal aortic aneurysm: update and look toward the future. Cardiovasc. Surg. 5: 256-265.

13. Thompson, R.W. 1996. Basic science of abdominal aortic aneurysms: emerging therapeutic strategies for an unresolved clinical problem. Curr. Opin. Cardiol. 11:504-518.

14. Baxter, B.T., G.S. McGee, V.P. Shively, I.A. Drummond, S.N. Dixit, M. Yamauchi, and W.H. Pearce. 1992. Elastin content, cross-links, and mRNA in normal and aneurysmal human aorta. J. Vasc. Surg. 16:192-200.

15. Gandhi, R.H., E. Irizarry, J.O. Cantor, S. Keller, G.B. Nackman, V.J. Halpern, K.M. Newman, and M.D. Tilson. 1994. Analysis of elastin cross-linking and the connective tissue matrix of abdominal aortic aneurysms. Surgery. 115:617-620

16. Tilson, M.D. 1988. Histochemistry of aortic elastin in nonspecific abdominal aortic aneurysm disease. Arch. Surg. 123:503-505.

17. Shapiro, S.D., S.K. Endicott, M.A. Province, J.A. Pierce, and E.J. Campbell. 1991. Marked longevity of human lung parenchymal elastic fibers deduced from prevalence of $\mathrm{D}$-aspartate and nuclear weapons-related radiocarbon. J. Clin. Invest. 87:1828-1834.

18. Lefevre, M., and R.B. Rucker. 1980. Aorta elastin turnover in normal and hypercholesterolemic Japanese quail. Biochim. Biophys. Acta. 630:519529.

19. Campa, J.S., R.M. Greenhalgh, and J.T. Powell. 1987. Elastin degradation in abdominal aortic aneurysms. Atherosclerosis. 65:13-21.

20. Dobrin, P.B., W.H. Baker, and W.C. Gley. 1984. Elastolytic and collagenolytic studies of arteries: implications for the mechanical properties of aneurysms. Arch. Surg. 119:405-409.

21. Dobrin, P.B., and R. Mrkvicka. 1994. Failure of elastin or collagen as possible critical connective tissue alterations underlying aneurysmal dilatation. Cardiovasc. Surg. 2:484-488.

22. Powell, J.T. 1990. Dilatation through loss of elastin. In The Cause and Management of Aneurysms. R.M. Greenhalgh, J.M. Mannick, and J.T. Powell, editors. W.B. Saunders, London. 89-96.

23. Koch, A.E., G.K. Haines, R.J. Rizzo, J.A. Radosevich, R.M. Pope, P.G. Robinson, and W.H. Pearce. 1990. Human abdominal aortic aneurysms. Immunophenotypic analysis suggesting an immune-mediated response. Am. J. Pathol. 137:1199-1213.

24. Brophy, C.M., J.M. Reilly, G.J. Smith, and M.D. Tilson. 1991. The role of inflammation in nonspecific abdominal aortic aneurysm disease. Ann. Vasc. Surg. 5:229-233.

25. Tilson, M.D. 1995. Similarities of an autoantigen in aneurysmal disease of the human abdominal aorta to a $36-\mathrm{kD}$ microfibril-associated bovine aortic glycoprotein. Biochem. Biophys. Res. Commun. 213:40-43.

26. Xia, S., K. Ozsvath, H. Hirose, and M.D. Tilson. 1996. Partial amino acid sequence of a novel 40-kD human aortic protein, with vitronectin-like, fibrinogen-like, and calcium binding domains: aortic aneurysm-associated protein-40 (AAAP-40) [human MAGP-3, proposed]. Biochem. Biophys. Res. Commun. 219:36-39.

27. Holmes, D.R., S. Liao, W.C. Parks, and R.W. Thompson. 1995. Medial neovascularization in abdominal aortic aneurysms: a histopathologic marker of aneurysmal degeneration with pathophysiologic implications. J. Vasc. Surg. 21: $761-772$

28. Lopez-Candales, A., D.R. Holmes, S. Liao, M.J. Scott, S.A. Wickline, and R.W. Thompson. 1997. Decreased vascular smooth muscle cell density in medial degeneration of human abdominal aortic aneurysms. Am. J. Pathol. 150: 993-1007.

29. Newman, K.M., J. Jean-Claude, H. Li, W.G. Ramey, and M.D. Tilson. 1994. Cytokines that activate proteolysis are increased in abdominal aortic aneurysms. Circulation. 90:224-227.

30. Koch, A., S. Kunkel, W. Pearce, M. Shah, D. Parikh, H. Evanoff, G. Haines, M. Burdick, and R. Strieter. 1993. Enhanced production of the chemotactic cytokines interleukin- 8 and monocyte chemoattractant protein-1 in human abdominal aortic aneurysms. Am. J. Pathol. 142:1423-1431.

31. Holmes, D.R., W. Wester, R.W. Thompson, and J.M. Reilly. 1997. Prostaglandin E2 synthesis and cyclooxygenase expression in abdominal aortic aneurysms. J. Vasc. Surg. 25:810-815.

32. Thompson, R.W., D.R. Holmes, R.A. Mertens, S. Liao, M.D. Botney, R.P. Mecham, H.G. Welgus, and W.C. Parks. 1995. Production and localization of 92-kilodalton gelatinase in abdominal aortic aneurysms. An elastolytic metalloproteinase expressed by aneurysm-infiltrating macrophages. J. Clin. Invest. 96:318-326.

33. Reilly, J.M., G.A. Sicard, and C.L. Lucore. 1994. Abnormal expression of plasminogen activators in aortic aneurysmal and occlusive disease. J. Vasc. Surg. 19:865-872.

34. Schneiderman, J., G.M. Bordin, I. Engelberg, R. Adar, D. Seiffert, T. Thinnes, E.F. Bernstein, R.B. Dilley, and D.J. Loskutoff. 1995. Expression of fibrinolytic genes in atherosclerotic abdominal aortic aneurysm wall. A possible mechanism for aneurysm expansion. J. Clin. Invest. 96:639-645.

35. Matrisian, L.M. 1990. Metalloproteinases and their inhibitors in matrix remodeling. Trends Genet. 6:121-125.

36. Woessner, J.F., Jr. 1991. Matrix metalloproteinases and their inhibitors in connective tissue remodeling. FASEB (Fed. Am. Soc. Exp. Biol.) J. 5:21452154 .

37. Senior, R.M., G.L. Griffin, C.J. Fliszar, S.D. Shapiro, G.I. Goldberg, and H.G. Welgus. 1991. Human 92- and 72-kilodalton type IV collagenases are elastases. J. Biol. Chem. 266:7870-7875.

38. Woessner, J.F., Jr. 1995. Matrilysin. Methods Enzymol. 248:485-495.

39. Shapiro, S.D., D.K. Kobayashi, and T.J. Ley. 1993. Cloning and characterization of a unique elastolytic metalloproteinase produced by human alveolar macrophages. J. Biol. Chem. 268:23824-23829.

40. Herron, G.S., E. Unemori, M. Wong, J.H. Rapp, M.H. Hibbs, and R.J. Stoney. 1991. Connective tissue proteinases and inhibitors in abdominal aortic aneurysms: involvement of the vasa vasorum in the pathogenesis of aortic aneurysms. Arterioscler. Thromb. 11:1667-1677.

41. McMillan, W.D., B.K. Patterson, R.R. Keen, V.P. Shively, M. Cipollone, and W.H. Pearce. 1995. In situ localization and quantification of mRNA for $92-\mathrm{kD}$ type IV collagenase and its inhibitor in aneurysmal, occlusive, and normal aorta. Arterioscler. Thromb. Vasc. Biol. 15:1139-1144.

42. McMillan, W.D., B.K. Patterson, R.R. Keen, and W.H. Pearce. 1995. In situ localization and quantification of seventy-two-kilodalton type IV collagenase in aneurysmal, occlusive, and normal aorta. J. Vasc. Surg. 22:295-305.

43. Brophy, C.M., W.H. Marks, J.M. Reilly, and M.D. Tilson. 1991. Decreased tissue inhibitor of metalloproteinases (TIMP) in abdominal aortic aneurysm tissue: a preliminary report. J. Surg. Res. 50:653-657.

44. Knox, J.B., G.K. Sukhova, A.D. Whittemore, and P. Libby. 1997. Evidence for altered balance between matrix metalloproteinases and their inhibitors in human aortic diseases. Circulation. 95:205-212.

45. Halpert, I., U.I. Sires, J.D. Roby, S. Potter-Perigo, T.N. Wight, S.D. Shapiro, H.G. Welgus, S.A. Wickline, and W.C. Parks. 1996. Matrilysin is expressed by lipid-laden macrophages at sites of potential rupture in atherosclerotic lesions and localizes to areas of versican deposition, a proteoglycan substrate for the enzyme. Proc. Natl. Acad. Sci. USA. 93:9748-9753.

46. Matsumoto, S., T. Kobayashi, M. Katoh, S. Saito, Y. Ikeda, M. Kobori, Y. Masuho, and T. Watanbe. 1998. Expression and localization of matrix metalloproteinase-12 in the aorta of cholesterol-fed rabbits. Am. J. Pathol. 153:109119.

47. Carmeliet, P., L. Moons, R. Lijnen, M. Baes, V. Lemaitre, P. Tipping, A. Drew, Y. Eeckhout, S. Shapiro, F. Lupu, et al. 1997. Urokinase-generated plasmin activates matrix metalloproteinases during aneurysm formation. Nat. Genet. 17:439-444.

48. Armitage, P and G. Berry 1994. Statistical Methods in Medical Research. Blackwell Scientific Publications, Cambridge. 207-228.

49. Chomczynski, P., and N. Sacchi. 1987. Single-step method of RNA isolation by acid guanidinium thiocyanate-phenol-chloroform extraction. Anal. Biochem. 162:156-159.

50. Belaaouaj, A., J.M. Shipley, D.K. Kobayashi, D.B. Zimonjic, N. Popescu, G.A. Silverman, and S.D. Shapiro. 1995. Human macrophage metalloelastase. Genomic organization, chromosomal location, gene linkage, and tissue-specific expression. J. Biol. Chem. 270:14568-14575.

51. Shapiro, S.D., G.L. Griffin, D.J. Gilbert, N.A. Jenkins, N.G. Copeland, H.G. Welgus, R.M. Senior, and T.J. Ley. 1992. Molecular cloning, chromosomal localization, and bacterial expression of a murine macrophage metalloelastase. J. Biol. Chem. 267:4664-4671.

52. Shipley, J.M., G.A. Doyle, C.J. Fliszar, Q.Z. Ye, L.L. Johnson, S.D. Shapiro, H.G. Welgus, and R.M. Senior. 1996. The structural basis for the elastolytic activity of the $92-\mathrm{kD}$ and $72-\mathrm{kD}$ gelatinases. Role of the fibronectin type II-like repeats. J. Biol. Chem. 271:4335-4341.

53. Shapiro, S.D., C.J. Fliszar, T.J. Broekelmann, R.P. Mecham, R.M. Senior, and H.G. Welgus. 1995. Activation of the $92-\mathrm{kD}$ gelatinase by stromelysin and 4-aminophenylmercuric acetate. Differential processing and stabilization of the carboxyl-terminal domain by tissue inhibitor of metalloproteinases (TIMP). J. Biol. Chem. 270:6351-6356.

54. Huebner, P.F. 1976. Determination of elastolytic activity with elastinrhodamine. Anal. Biochem. 74:419-429.

55. Werb, Z., M.J. Banda, and P.A. Jones. 1980. Degradation of connective tissue matrices by macrophages. I. Proteolysis of elastin, glycoproteins, and collagen by proteinases isolated from macrophages. J. Exp. Med. 152:1340-1357.

56. Shipley, J.M., R.L. Wesselschmidt, D.K. Kobayashi, T.J. Ley, and S.D. Shapiro. 1996. Metalloelastase is required for macrophage-mediated proteolysis and matrix invasion in mice. Proc. Natl. Acad. Sci. USA. 93:3942-3946.

57. Hautamaki, R.D., D.K. Kobayashi, R.M. Senior, and S.D. Shapiro. 1997. Requirement for macrophage elastase for cigarette smoke-induced emphysema in mice. Science. 277:2002-2004.

58. Mecham, R.P., T.J. Broekelmann, C.J. Fliszar, S.D. Shapiro, H.G. Welgus, and R.M. Senior. 1997. Elastin degradation by matrix metalloproteinases: cleavage site specificity and mechanisms of elastolysis. J. Biol. Chem. 272: 18071-18076.

59. Emonard, H., and W. Hornebeck. 1997. Binding of $92 \mathrm{kD}$ and $72 \mathrm{kD}$ progelatinases to insoluble elastin modulates their proteolytic activation. Biol. Chem. 378:265-271. 